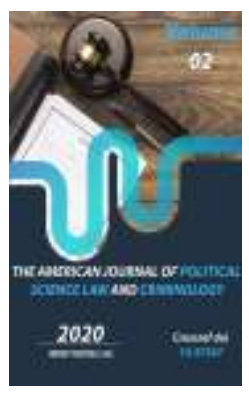

\title{
The Concept Of Biotechnology And Its Legal Nature
}

\author{
Bakhtiyor Usubjonovich Akhmadjonov \\ Lawyer Of Ferghana State University, Candidate In Law (PhD), Ferghana Region, Republic Of \\ Uzbekistan
}

Journal Website:

http://usajournalshub.c

om/index,php/tajpslc

Copyright: Original

content from this work

may be used under the

terms of the creative

commons attributes

4.0 licence.

\section{ABSTRACT}

The article comprehensively analyzes the concept of biotechnology and issues of its legal nature with the help of scientific literature and other sources. However, the study has developed a variety of biotechnologies that can be applied in the near future, including hybridization of somatic cells with protoplasts for selection processes, gene transfer to plant cells, mutagenesis and cell-level selection methods are presented in detail to be promising.

\section{KEYWORDS}

Biotechnology, selection, mechanism, legal nature, hybridization, biochemistry, cell.

\section{INTRODUCTION}

In the second half of the twentieth century, as a result of advances in fundamental research areas - biochemistry, bioorganic chemistry and molecular biology, certain factors have been created to control certain mechanisms of cell life. However, the biotechnological processes used in various areas of human activity: baking, wine production, preparation of dairy products have been known since ancient times. The possibility of genetic manipulation with plant cells has expanded with the advent of the method of obtaining isolated protoplasts (protoplast - everything present in the cell). This situation ensured the reality of performing microsurgery in cells, abandoning individual parts of the cell, transplanting a foreign organism, and inserting new genetic information into the DNA of the object under study. In this case, the ability of the bare protoplast to cover the cell as a layer of 
cellulose serves to regenerate the plant, and this is a radical tool in the reconstruction of the plant.

\section{RESEARCH METHODS}

Various biotechnologies have now been developed that can be applied in the near future. In particular, for selection processes, hybridization of somatic cells by addition to protoplasts, gene transfer to plant cells, mutagenesis (occurrence of a process of hereditary change under the influence of natural and artificial mutagenic factors) and cell-level selection methods may be promising $[1$, p.232].

Unfortunately, the current achievements of biotechnology in agriculture are not commendable, on the basis of which a small number of products are developed, but researchers have no doubt about the prospects of this direction, and therefore the development of biotechnology in the US, Japan, Germany, France, UK, Brazil, India is receiving a lot of attention in China and other countries.

Practices for the development of feed, special food products, medical products and recycling of industrial waste are being organized on the basis of biotechnological methods. Biotechnological methods create the possibility of vegetative propagation of the plant, that is, they promote the regeneration of the plant under the conditions of a biotechnological system from a group of cells and even a single cell. At the same time in the context of consumption, in one case the plant cells multiply indefinitely, the biome grows rapidly, and in the second case they differentiate, forming the outer shell, forming a state of flowering and reproduction.

In this sense, biotechnological research can be carried out in the following areas:
- Creation of plant varieties resistant to adverse factors;

- Development of biological means of pest control, their toxic products produced by natural enemies and parasites, as well as living organisms and etc. [2, p.16].

\section{RESULTS AND DISCUSSIONS}

Skin and cell (biotechnology) methods have been developed for a number of medicinal and agricultural plants today. In the traditional understanding, biotechnology is the science of methods and technologies for the production of various useful and necessary materials and products using natural biological objects (microorganisms, plant and animal cells), cell parts (cell membranes, ribosomes, mitochondria, chloroplasts) and processes.

The roots of biotechnology go back a long way and are mainly related to the processes of preparation of various food products using yeasts. For example, biotechnological processes such as fermentation with the participation of microorganisms were widely used in ancient Babylon, as evidenced by the records of brewing beer found in 1981 as a result of excavations in Babylon.

The research and work of Louis Pasteur (18221895), a French scientist in biotechnology and founder of modern microbiology and immunology, rose to the level of science. The twentieth century saw the rapid development of molecular biology and genetics as a result of the application of the achievements of chemistry and physics. An important area of research in this area is the development of methods for the cultivation of plant and animal cells. Furthermore, while until recently only bacteria and fungi were grown for industrial purposes, today it is possible not only to grow any cell to produce biomass, but to control 
their development, and this is especially evident in plants. Indeed, the development of biotechnological methods that allow the direct manipulation of genes, the creation of new products, organisms and change the properties of existing ones has been the result of new scientific and technological approaches. The main purpose of the application of these methods is to make full use of the potential of living organisms for the benefit of human economic activity.

In the 1970s, important areas of biotechnology, such as genetic and cellular engineering, emerged and began to develop actively, resulting in a "new biotechnology" that differed from "old" biotechnology and was based on traditional microbiological processes. While the production of alcohol in the fermentation process is an "old" biotechnology, the use of yeasts improved by genetic engineering methods to increase the amount of alcohol in the process is a "new" biotechnology. Genetic and cell engineering are important methods based on modern biotechnology. Methods of cell engineering focus on the design of new types of cells. They can be used to restore cell viability in individual fragments of different cells, to combine cells that belong to different cells and are considered genetic material for both primary cells, and for other operations [3, p.37].

Genetic engineering methods focus on constructing new, naturally occurring gene combinations. As a result of the application of genetic engineering methods, recombinant (modified) RNA and DNA molecules can be obtained, and for this purpose separate genes (coded necessary product) are isolated from the cell of an organism. After certain manipulations with genes are carried out, they are introduced into other organisms (bacteria, yeasts and ants), resulting in the acquisition of a new gene and the creation of a modified end product with the desired directional characteristics for humans. In other words, genetic engineering makes it possible to obtain a defined (expected) quality called a modified or genetically modified organism or a "transgenic" plant and animal.

Genetic engineering is widely used today, mainly in agriculture and medicine. It is known that people have always pondered over how to manage nature and look for ways to do it, for example, to get useful qualities: higher yields, larger and more delicious fruits or a plant with cold tolerance. The main method used for this purpose since ancient times is selection. This method is still widely used today and is aimed at creating and improving the existence of cultivated plant varieties, pet breeds and strains of microorganisms along with beneficial traits and characteristics for humans.

Selection is based on the selection of plants (animals) with acceptable traits and the subsequent interbreeding of such organisms, while genetic engineering allows direct interference with the genetic apparatus of the cell. It should be noted that it is much more difficult to obtain a hybrid with a combination of beneficial traits sought during traditional selection, so that the offspring will pass large fragments of the genome of each parent, while genetic engineering techniques usually allow to work with one or more genes does not affect the activity of other genes. As a result, it is possible to add to it one or more useful designations without losing other useful properties of the plant, which is very valuable for the creation of new varieties and new forms of plants. The application of genetic engineering has made it possible to modify a number of characteristics of a plant, such as its resistance to climate and external influences, its resistance to pests or diseases that spread to certain areas. Scientists even admit that there is hope to create a fire-resistant tree 
species. Extensive research is being conducted to improve the consumption of various agricultural products, such as corn, soybeans, potatoes, tomatoes, peas [4, p.146].

Historically, there have been "three waves" of gene-modified plant creation:

The first wave - the late 1980s - was the creation of new feature plants resistant to viruses, pests or herbicides. In the "first wave" plants, only one additional gene is introduced and forced to "work", that is, one additional protein is mixed. "Beneficial" genes were "taken" from plant viruses (to create resistance to the virus) or from soil bacteria (against pests, herbicides).

The second wave - the early 2000 s - was the creation of a plant with new consumption properties: fat-enhanced products with meaningful and modified fats, fruits and vegetables with large amounts of vitamins, and so on.

Nowadays, scientists are creating a "third wave" of plants that will be on the market in the next 10 years: vaccine-plants for industrial production, bioreactor-plants (for plastics, paints, technical oils and various other components), plants for medicines, and so on. In breeding, the work of genetic engineering has a different meaning. At the modern level of technology, the creation of genetically transgenic animals with a specific goal remains an achievable goal. For example, an animal gene (e.g., growth hormone) that was once valuable is introduced into a large number of cultivated bacteria. Another example: transgenic goats with the appropriate gene produce a VIII-factor-specific protein, which prevents bleeding in patients suffering from hemophilia. Transgenic animals produce such proteins relatively quickly, and the method to achieve this is cheaper than the traditional method.
In the late 1990s, U.S. scientists began to use the method of obtaining farm animals based on the method of cloning embryonic cells, although this direction still requires serious research. On the contrary, xenotransplantation has achieved great results in the field of transplantation of an organism from one organism to another.

Scientists also suggest that gene transfer reduces human allergies to cow's milk. Targeted alterations in cow's DNA also lead to a reduction in strong fatty acids and cholesterol in milk. The risk of using genetically modified organisms is characterized by two aspects: the risk of food to human health and the environmental risk. Therefore, an important step in creating a genetically modified product is to conduct a comprehensive examination of the product in order to eliminate the risk of allergenic proteins, toxins or any new hazardous components.

Along with its widespread use in agriculture, a whole pharmaceutical industry system based on genetic engineering, called the "DNA industry" and representing a modern branch of biotechnology, emerged. A quarter of all medicines used in the world today contain plant elements. Genetically modified plants are a cheap and safe source for both humans and animals in obtaining fully functional medicinal proteins (antibodies, vaccines, enzymes, etc.). Examples of genetic engineering in medicine include human insulin, erythropoietin (hormones that promote the formation of erythrocytes in the brain bone. The physiological role of this hormone is to regulate erythrocyte production based on the body's need for oxygen) or the use of genetically modified bacteria in experimental mice development [5, p.22-34]. 
The development of genetic engineering methods based on the creation of recombinant DNA has led to a "biotechnological explosion". Due to scientific advances in this field, not only the creation of "biological reactors", transgenic animals, genetically modified plants, but also genetic certification (as a rule, the impact of human genotype on birth to various diseases, various adverse effects on a particular drug, as well as specific activity a thorough study and analysis of the propensity for species) has also become possible. Genetic certification allows the detection and reduction of cardiovascular and oncological diseases, research and elimination of neurodegenerative diseases and the aging process, identification of neuro-physiological features of the individual at the molecular level, diagnosis of genetic diseases, development of DNA vaccines, genotherapy of various diseases [6, p.26-34].

In the twentieth century, in many countries around the world, major medical efforts have focused on combating infectious diseases, reducing young child mortality, and raising life expectancy. In the developed countries, the health care system has made some progress in this direction, with a strong focus on the treatment of chronic diseases, cardiovascular diseases and oncological diseases, which is why this group of diseases has a high mortality rate. At present, efforts are underway to find new methods and approaches. Science has shown that heredity plays a major role in the development of ischemic heart disease, anemia, inflammatory bowel disease of the stomach and duodenum, psoriasis, bronchial asthma and other similar diseases. It is obvious that in order to effectively treat and prevent these diseases, all specialists need to know the effects of external and hereditary factors, which does not apply to medicine without the development of biotechnological methods. In recent years, this direction has become a priority and is developing rapidly.

The reliability of genetic research based on biotechnological orientation is equally important, as about 4,000 species of hereditary diseases have been identified to date, $5-5.5 \%$ of children are born with hereditary or congenital diseases. Less than $30 \%$ of infant deaths occur during pregnancy and the postpartum period as a result of congenital malformations and hereditary diseases. In the 205 and 30s, human-related diseases are becoming more common. This is happening under the influence of various factors: living conditions, harmful habits, the consequences of transplanted diseases.

There is now a practical opportunity to significantly reduce and minimize the negative impact of hereditary factors. Medical genetics explains that the cause of many gene mutations is an unfavorable environmental effect, which in turn can reduce cancer, allergies, cardiovascular disease, diabetes, mental illness, and even some infectious diseases by solving environmental problems. At the same time, scientists have been able to identify genes that are associated with the manifestation of various pathologies and prolong life. In the use of medical genetics methods, good results were achieved in the treatment of $15 \%$ of diseases, and a significant improvement was observed in $50 \%$ of diseases.

It should be noted that significant advances in genetics have made it possible to study the genetic structure of an organism at the molecular level, but also to see the nature of many serious diseases in humans, from illumination to gene therapy. In addition, on the basis of medical-genetic knowledge has made it possible to diagnose hereditary diseases at an early stage and prevent hereditary pathology in a timely manner. 
Currently, an important area of medical genetics is the development of new methods for the diagnosis of hereditary diseases. Today, the initial implantation diagnosis - a method of diagnosing an embryo at an early stage of internal development - comes as no surprise. The geneticist is able to isolate a single cell in the unborn child without endangering his or her life, to determine its exact diagnosis, or to warn of a predisposition to a particular hereditary disease [7].

As a theoretical and clinical science, genetic medicine continues to develop rapidly in various fields: the study of the human genome, cytogenetics, molecular and biochemical genetics, immunogenetics, developmental genetics, reproductive genetics, clinical genetics. The wider use of biotechnological methods in pharmaceuticals and medicine has given rise to a new concept of "personalized medicine" in which the client's treatment is based on individual, including his genetic characteristics, and even the drugs used in treatment are prepared individually based on each patient's condition. The processes of cell hybridization and obtaining hybrids have not yet been fully studied and analyzed, but it is important to note that with their help it has been possible to develop individual clonal antibodies.

\section{CONCLUSION}

Although much progress has been made in the field of biotechnology today, it can be observed that there is no legal regulation of the industry and the relationships that arise in it, and that the system of relations is left out of the legal order. Of course, biotechnology as a separate area of research requires a legally complex regulation, which should cover all aspects and areas of biotechnology. Therefore, the adoption of the Law of the Republic of Uzbekistan "On Biotechnology" and the concept of biotechnology, the requirements for its implementation, the procedure for licensing and patenting of biotechnology.

\section{REFERENCES}

1. Imomov N.F. The legal status of a new variety and breed as an object of intellectual property. - Tashkent, TSUL, 2010. $-232 \mathrm{p}$.

2. Kontsevenko A.S. Legal regulation of biomedical research and the application of new biotechnologies in the European Union: Abstract dissertation candidate of juridical sciences. -M, $2011 .-16 \mathrm{p}$.

3. Melikhov A.B. Biotechnology and civil circulation // Abstracts of the twelfth regional conference of young researchers of the Volgograd region. 2007. 13-16 November. - Volgograd: Publishing house of the Volgograd State University, 2008. - P. 37.

4. Sipatova D.N. Human cloning as a crime: international aspects. VI international scientific conference of students and graduate students // Sat. articles of the Moscow Institute of Economics, Management and Law. M., 2008.- P.146.

5. Belikova K.M. Organizational and legal development of biotechnology in Brazil on the basis of accumulated scientific information in the context of ensuring national security // Law and Politics. - 2019. - No.6. - P. 22 - 34.

6. Inshakova A.O., Ryzhenkov A.Ya., Bogdanova ETC. Legal protection of biotechnologies in the Russian Federation: advantages of patenting and criteria for patentability. // Western Volgog. state unthat. Ser. 5, Jurisprud.-2015.-№ 3 (28). - p. 26-34.

7. Edna T. Kimura, Gilson S. Baía. Rede ONSA e o Projeto Genoma Humano do Câncer: 
The American Journal of Political Science Law and Criminology (ISSN - 2693-0803)

Published: November 09, 2020 | Pages: 1-7

Doi: https://doi.org/10.37547/tajpslc/Volume02Issue11-01

Contribuição ao Genoma Humano. // Arq

Bras Endocrinol Metab vol. 46 no. 4. São

Paulo.

Aug.

2002.

http://dx.doi.org/10.1590/So004-

27302002000400003.

URL:

http://www.scielo.br/ scielo.

php?script=sci_arttext\&pid=So004-

27302002000400003 